\title{
Penentuan ketinggian dan kecepatan minimum benda pada track melingkar vertikal
}

\author{
Indra Yahdi Putra, Santi Fani Sigalingging, dan Dandan Luhur Saraswati \\ Program Pendidikan Fisika Universitas Indraprasta PGRI \\ Jl. Raya Tengah No. 80, Gedong, Pasar Rebo Jakarta Timur \\ Surat-e: indra.yahdi@gmail.com, santivani92@gmail.com
}

Tujuan dari penelitian adalah untuk menentukan ketinggian dan kecepatan minimum benda pada track melingkar vertikal sehingga benda tidak terjatuh, seperti yang terjadi pada gerakan Roller Coaster. Penelitian ini menggunakan alat peraga sederhana yang dibuat semirip mungkin dengan track Roller Coaster untuk membuat simulasi gerak yang terjadi. Gerak benda yang terjadi dianalisis menggunakan software tracker, dan menggunakan perhitungan manual dengan menggunakan persamaan-persamaan yang berlaku pada gerak benda yang terjadi. Data yang diperoleh dari hasil perhitungan manual didapat bahwa agar benda dapat melintasi track tanpa terjatuh kecepatan minimal benda yang harus dicapai adalah $1,2 \mathrm{I} \mathrm{m} / \mathrm{s}$ dan ketinggian minimal benda yang harus dipenuhi menurut hasil perhitungan manual adalah 2,5 kali dari jari jari lintasan melingkar (2,5R). Untuk kasus ini karena jari-jari lintasan melingkar adalah I5 $\mathrm{cm} / 0,15 \mathrm{~m}$ maka ketinggian minimal adalah $37,5 \mathrm{~cm}$ atau $0,375 \mathrm{~m}$. Berdasarkan hasil percobaan menggunakan alat peraga, ketinggian benda agar tidak terjatuh dari lintasan adalah $50 \mathrm{~cm}$ dan analisis menggunakan software tracker didapat bahwa kecepatan benda ketika bergerak pada lintasan adalah $2,26 \mathrm{~m} / \mathrm{s}$ juga hasil perhitungan manual kecepatan benda pada saat dilintasan adalah $2,3 \mathrm{I} \mathrm{m} / \mathrm{s}$. Dari hasil kedua perhitungan tersebut dapat kita simpulkan bahwa persamaan-persamaan yang digunakan untuk mencari ketinggian dan kecepatan benda pada track melingkar vertikal sudah sesuai, karena kecepatan yang didapat dari hasil perhitungan mendukung hasil dari alat peraga.

The purpose of this study is to determine the height and minimum speed of the object on the vertical circular track so that objects do not fall, as happened in the Roller Coaster movement. This study uses simple props made as closely as possible with the Roller Coaster track to make the simulation of motion taking place. The motion of objects that occur is analyzed using the tracker software and using manual calculations using equations that apply to the motion of objects that occur. The data obtained from the results of manual calculations found that for objects to cross the track without falling, the minimum speed of the object to be achieved is I. $2 \mathrm{I} \mathrm{m} / \mathrm{s}$ and the minimum height of the object according to the results of manual calculations is 2.5 times of the radius of circular trajectory (2.5R), for this case because the radius of the circular path is $15 \mathrm{~cm} / 0.15 \mathrm{~m}$ then the minimum height is $37.5 \mathrm{~cm}$ or $0.375 \mathrm{~m}$. Based on experimental results using props, the height of the object in order not to fall from the track is $50 \mathrm{~cm}$ and analysis using the tracker software found that the velocity of objects when moving on the track is $2.26 \mathrm{~m} / \mathrm{s}$ and also the result of manual calculation of the velocity of the object at that time is $2.3 \mathrm{I} \mathrm{m} / \mathrm{s}$. From the result of both calculations can be concluded that the equations used to find the height and velocity of the object on the vertical circular track are appropriate, since the speed obtained from the calculation supports the results of props showing the object passing through the path without falling over the limit minimums that have been taken into account.

Kata kunci: Gerak Melingkar, Roller coaster, Tracker, alat peraga 


\section{Pendahuluan}

Kesulitan yang sering dihadapi guru dalam pembelajaran di kelas adalah bagaimana materi pelajaran yang disampaikan dapat dikuasai secara tuntas oleh peserta didik. Kesulitan tersebut dikarenakan kecerdasan peserta didik beragam dan latar belakang yang berbeda satu sama lain. Oleh karena itu, pemberian pengalaman belajar secara langsung melalui penggunaan dan pengembangan keterampilan proses serta sikap ilmiah dapat diimplementasikan dengan menciptakan alat peraga, untuk menjangkau peserta didik yang memiliki kesukaran dalam pemahaman materi.

Mempelajari ilmu fisika dapat dilakukan melalui dua pendekatan yaitu analitis dan pembuktian melalui eksperimen. Belajar fisika peserta didik diharapkan tidak hanya mampu matematis dan teori tetapi peserta didik juga dapat menerapkannya dalam kehidupan sehari-hari dan bereksperimen. Kebanyakan konsep yang dipelajari dalam fisika bersifat abstrak dan hanya berfokus pada materi soal matematis yang dijelaskan di kelas. Untuk memahami konsep materi yang bersifat abstrak, diperlukan kreativitas guru dalam memilih media pembelajaran yang tepat. Salah satu komponen media pembelajaran yaitu alat peraga.

Roller coaster merupakan salah satu wahana permainan yang sering kita jumpai. Wahana ini pertama kali ada di Disne Land, Amerika Serikat. Wahana ini merupakan permainan berupa kereta yang dipacu dengan kecepatan tinggi pada suatu rel khusus. Rel ini ditopang oleh rangka baja sedemikian rupa sehingga rel kokoh, dan tidak mudah roboh.

Lintasan rel roller coaster ada yang datar, dan banyak pula yang berbentuk melingkar vertikal. Hal ini tentu membutuhkan analisis fisika agar roller coaster bisa dijalankan dengan aman, dan tidak membahayakan para pengunjung. Salah satu aspek yang terpenting dalam analisis wahana ini adalah memperhitungkan ketinggian dan kecepatan minimumnya. Dengan mengetahui kecepatan dan ketinggian minimum inilah kereta rollet coaster bisa berjalan di lintasan vertikal tanpa terjatuh.

Pada penelitian ini akan dibuat simulasi lintasan roller coaster dengan skala kecil. Kemudian akan dilakukan analisis terkait ketinggian dan kecepatan minimumnya.

\section{Kajian Pustaka}

Gerak melingkar terjadi ketika benda atau partikel bergerak sepanjang lintasan melengkung, arah kecepatannya berubah-ubah. Beberapa contoh dari gerak melingkar pada benda seperti mobil mengitari lintasan atau jalanan yang melengkung, satelit yang bergerak dalam orbit dan gerak roller coaster ketika melintasi lintasan melingkar.
Gerak melingkar merupakan fenomena menarik yang terjadi pada kehidupan sehari-hari seperti pada gerak roller coaster dan dapat dijelaskan dengan menggunakan ilmu fisika. Fenomena seperti ini terkadang sulit untuk dijelaskan jika hanya dengan metode ceramah ketika di dalam kelas, dibutuhkan alat bantu seperti model atau alat peraga yang dapat dilihat dan diteliti langsung oleh siswa.

Menurut hasil penelitian Ref [I], siswa mendapatkan hasil belajar yang lebih baik ketika guru membuat suatu alat peraga untuk menyampaikan materi. Hasil belajar siswa meningkat serta pembelajaran pun menjadi lebih efektif. Penggunaan alat peraga ini juga membuat siswa menjadi lebih aktif dan terlibat secara langsung dalam proses pembelajaran.

Peristiwa gerakan roller coaster ketika melintasi lintasan melingkar vertikal cukup menarik, ada berbagai macam kejadian fisika yang terjadi di sana. Menurut Ref [2] dan Ref [3] pada gerak benda ketika melewati lintasan melingkar vertikal dibutuhkan kecepatan yang cukup dan ketinggian yang cukup agar benda tidak terjatuh ketika melewati lintasan.

Menurut Ref [4] percobaan atau eksperimen dalam pembelajaran IPA merupakan langkah konkrit guru dalam menghadirkan fakta-fakta keilmuan dalam pembelajaran. Pembuktian fakta ilmuwan ada yang bersifat nyata maupun abstrak. Pada pembelajaran IPA, ada beberapa kompetensi dasar (KD) yang bersifat abstrak, seperti cahaya, dan listrik. Pembelajaran materi cahaya dan listrik memerlukan media visualisasi agar mudah dipahami peserta didik.

Penelitian ini juga menggunakan software analisis Tracker. Beberapa penelitian di fisika banyak yang menggunakan software untuk membantu mencari fakta dan mendapatkan perhitungan yang lebih baik seperti pada jurnal [4], [5] dan [6]. Pada era teknologi seperti sekarang bantuan software seperti itu sangat membantu penelitian.

Pada percobaan ini juga bertujuan untuk membuktikan hukum kekekalan energi, namun benda yang bergerak pada lintasan melingkar vertikal membutuhkan energi yang cukup agar dapat melewati lintasan tanpa terjatuh $\mathrm{di}$ tengah lintasan. Energi yang dimiliki oleh benda meliputi energi potensial dan energi kinetik. Pada energi potensial ketinggian mempengaruhi besar kecilnya energi yang dihasilkan.

Selain hukum kekekalan energi pada percobaan ini juga menggunakan rumus dari gerak melingkar karena benda melewati lintasan yang berbentuk lingkaran. Pada benda yang bergerak melewati lintasan melingkar vertikal dibutuhkan kecepatan minimum yang harus dicapai agar benda tidak terjatuh pada saat melewati lintasan.

Perhitungan manual dengan menggunakan teori yang ada dibandingkan dengan percobaan yang dilakukan menggunakan alat peraga yang telah dibuat untuk menyerupai gerak benda seperti roller coaster yang 
melewati lintasan melingkar vertikal yang dianalisis dengan menggunakan software analysis tracker.

\section{Metode Penelitian/Eksperimen}

Penelitian ini menggunakan metode eksperimen, kegiatan yang dilakukan dalam penelitian ini yaitu pembuatan track atau jalur lintas benda yang hendak dilalui untuk pengambilan data. Pengambilan data dilakukan dengan mengambil video saat kegiatan praktik dilakukan kemudian hasil video dimasukkan ke dalam software tracker, dengan alur penelitian sebagai berikut:

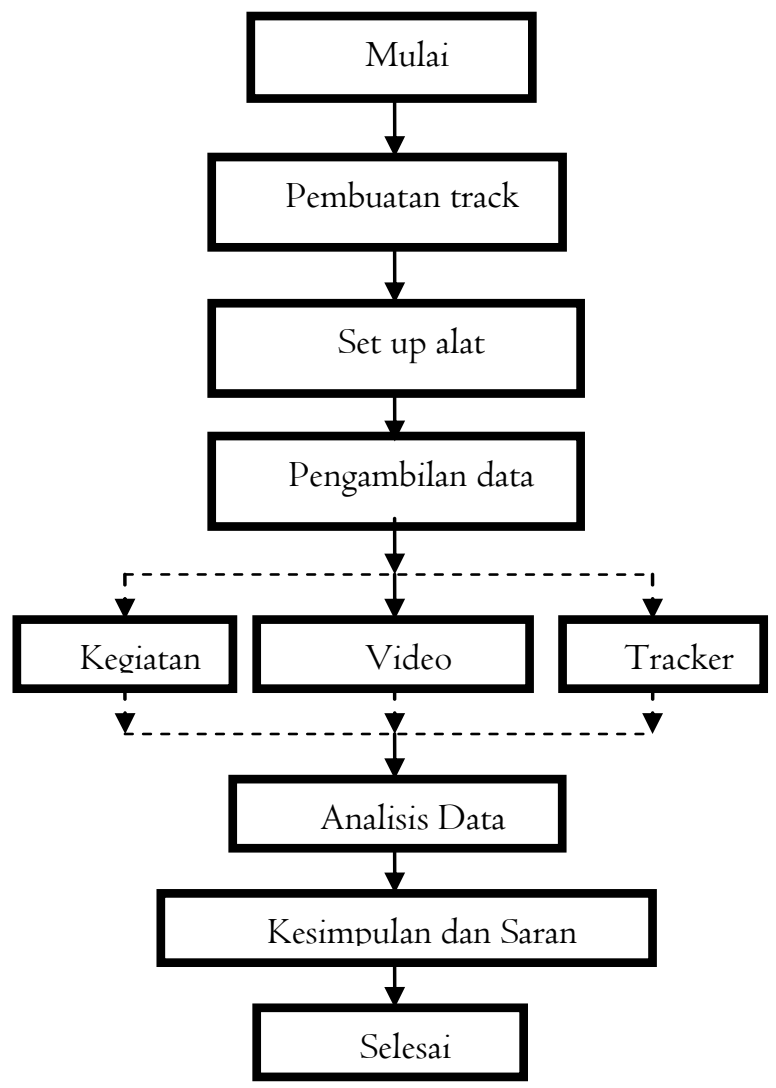

Gambar I. Diagram alir penelitian Esperimen.

Alat dan bahan yang digunakan dalam penelitian ini adalah:

a. Mobil mainan.

b. Lintasan $360 \mathrm{~cm}$

c. Kayu penyangga lintasan melingkar $10 \mathrm{~cm}$ ( 2 buah).

d. Penyangga lintasan lurus $20 \mathrm{~cm}$ (I buah)

e. Penyangga lintasan lurus $60 \mathrm{~cm}$ (I buah)

f. Double Tape

g. Perekam Video

h. Infraboard (I buah)

i. Gabus Penyanga tiang (I buah)
Prosedur eksperimen sebagai berikut:

a. Menyiapkan dan menyusun track hingga seperti gambar. Atur diameter pada track melingkar pada 30 $\mathrm{cm}$.

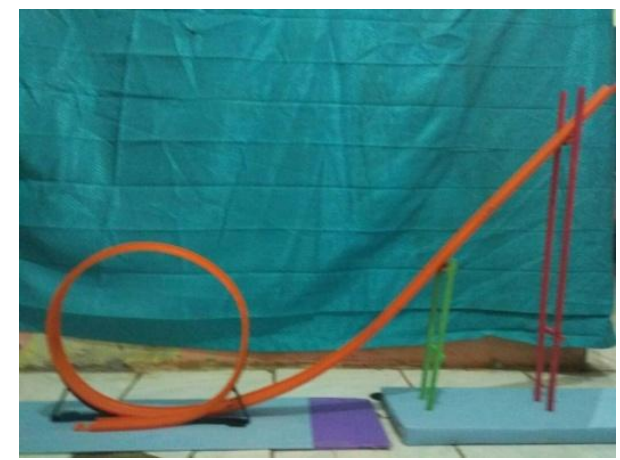

Gambar 2. Track yang telah disusun. Dokumen pribad

b. Mengatur diameter lingkaran track sebesar $30 \mathrm{~cm}$ dan tinggi track lurus sebesar $50 \mathrm{~cm}$.

c. Menyiapkan kamera yang digunakan untuk merekam jalannya benda pada track.

d. Mencoba meluncurkan benda beberapa kali dari ketinggian berbeda dimulai dari $30 \mathrm{~cm}$ sesuai dengan diameter lintasan melingkar dan rekam gerakan benda.

e. Lakukan langkah ke- 4 secara berulang hingga mendapatkan ketinggian yang pas dimana benda dapat melewati lintasan melingkar vertikal secara sempurna tanpa terjatuh.

f. Mencatat ketinggian benda ketika benda dapat melewati lintasan lingkaran vertical secara sempurna.

g. Memasukan video rekaman hasil benda yang dapat melewati lingkaran vertical sempurna yang telah direkam ke dalam software tracker untuk dianalisis.

h. Menjalankan video dan drag video untuk mengatur titik mulai dan titik akhir video yang ingin dianalisis.

i. Meng-klik Calibration Tools dan pilih Calibration Stick dan letakkan pada track agar software dapat mengetahui panjang lintasan yang sebenarnya.

j. Meng-klik object mass, kemudian tandai ke benda yang akan kita luncurkan.

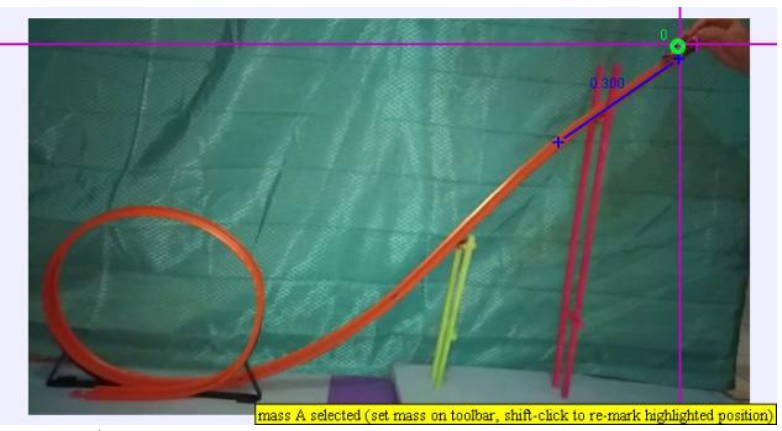

Gambar 4. Calibration tools (ungu), calibration stick (biru) dan object mass (titik hijau) Dokumen pribadi

k. Menganalisis benda yang meluncur dengan cara manual track yaitu menentukan titik-titik benda 
meluncur agar software dapat menganalisis pergerakan benda.

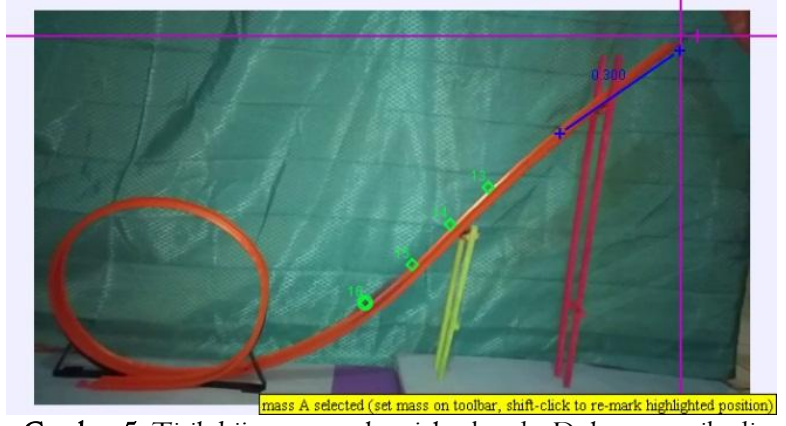

Gambar 5. Titik hijau merupakan jalur benda. Dokumen pribadi

Data yang dianalisis meliputi:

I. Energi Potensial $\left(E_{P}\right)$

2. Energi Kinetika $\left(E_{k}\right)$

3. Dinamika

4. Kekekalan Energi dalam gerak

5. Gaya sentipental

\section{Hasil Penelitian dan Pembahasan}

Ada 2 cara yang dilakukan dalam menganalisis hasil eksperimen ini. Pertama melakukan analisis data melalui perhitungan dengan menggunakan rumus-rumus yang berlaku pada eksperimen ini. Kedua melakukan analisis data melalui software tracker. Data yang didapat akan dibandingan apakah hasil yang didapat sama atau tidak.

Analisis melalui perhitungan dilakukan dengan mengumpulkan data yang didapat secara manual pada eksperimen. Data yang didapat seperti :

a. Diameter lingkaran $=30 \mathrm{~cm} / 0,3 \mathrm{~m}$

b. Ketinggian benda $=50 \mathrm{~cm} / 0,5 \mathrm{~m}$

c. Waktu benda ketika meluncur $=0,407 \mathrm{~s}$

d. Panjang $/$ keliling lintasan $=0,3 \pi$

e. Percepatan gravitasi $=9,8 \mathrm{~m} / \mathrm{s}^{2}$

Perhitungan menggunakan rumus-rumus hukum kekekalan energi, percepatan pada gerak melingkar, keliling lingkaran dan kecepatan benda diantaranya.

$$
\begin{aligned}
& E_{t}=E_{p}+E_{k} \\
& E_{p}=m g h \\
& E_{k}=\frac{1}{2} m v^{2} \\
& a_{c}=\frac{v^{2}}{r} \\
& S=2 \pi r \\
& v=\frac{s}{t} \\
& F=m a
\end{aligned}
$$

Keterangan.

$E_{t}=$ energi total benda (joule)

$E_{p}=$ energi potensial benda (joule)

$E_{k}=$ energi kinetik (joule)

$a_{c}=$ percepatan gerak melingkar $\left(\mathrm{rad} / \mathrm{s}^{2}\right)$

$g=$ gravitasi bumi $\left(\mathrm{m} / \mathrm{s}^{2}\right)$

$v=$ kecepatan $(\mathrm{m} / \mathrm{s})$

$m=\operatorname{massa}(\mathrm{kg})$

$S=$ jarak/keliling lingkaran (m)

$t=$ waktu (sekon)

Benda yang berjalan di lintasan akan memiliki energi total $\left(E_{t}\right)$ yang sama pada saat di atas lintasan $\left(E_{t} 1\right)$ dengan pada saat meluncur di lintasan melingkar vertikal ( $\left.E_{t} 2\right)$, sehingga $E_{t} 1=E_{t} 2 \cdot E_{t} 1$ merupakan gabungan energi potensial $\left(E_{p} 1\right)$ dan energi kinetik $\left(E_{k} 1\right)$ pada saat benda diam dan di atas lintasan sebelum meluncur, karena benda diam maka $v=0$ sehingga energi kinetik $\left(E_{k} 1\right)$ benda juga nol. Ketika benda di atas lintasan energi yang bekerja dapat kita tuliskan sebagai berikut.

$$
\begin{aligned}
& E_{t} 1=E_{p} 1+E_{k} 1 \\
& E_{t} 1=E_{p} 1+0 \\
& E_{t} 1=E_{p} 1 \\
& E_{t} 1=m g h_{1}
\end{aligned}
$$

Pada saat benda berada di atas lintasan melingkar vertikal energi total $\left(E_{t} 2\right)$ benda terdiri dari energi potensial $\left(E_{p} 2\right)$ dan energi kinetik $\left(E_{k} 2\right)$ karena benda sedang bergerak serta berada di ketinggian $30 \mathrm{~cm}$. sehingga dapat dituliskan sebagai berikut.

$$
E_{t} 2=E_{p} 2+E_{k} 2
$$

Setelah itu, dianalisis gaya yang ada ketika benda berada di atas lintasan melingkar vertikal. Terdapat gaya normal dan gaya gravitasi yang bekerja pada benda. Untuk mengetahui kecepatan minimal benda dan ketinggian minimal benda agar dapat melewati lintasan dengan sempurna maka gaya normal benda akan bernilai nol karena pada kecepatan minimumnya benda akan jatuh dan tidak bersentuhan dengan lintasan jika gaya normal benda nol, maka tidak ada gaya gesek yang terjadi sehingga benda jatuh. Pada gerak melingkar percepatan yang berlaku adalah percepatan sentripetal atau percepatan melingar. Untuk itu dapat dituliskan sebagai berikut.

$$
\begin{aligned}
& F_{\text {total }}=F_{N}+F_{g}=m a_{c} \\
& F_{\text {total }}=0+F_{g}=m a_{c} \\
& F_{g}=m a_{c}
\end{aligned}
$$




$$
\begin{aligned}
& m g=m \frac{v^{2}}{r} \\
& g=\frac{v^{2}}{r} \\
& v^{2}=g r \\
& v=\sqrt{g r}
\end{aligned}
$$

Kemudian menggunakan hukum kekekalan energi.

$$
\begin{aligned}
& E_{t} 1=E_{t} 2 \\
& m g h_{1}=m g h_{2}+\frac{1}{2} m v^{2}
\end{aligned}
$$

Subtitusikan persamaan (I8), karena nilai $m$ dan $g$ sama maka kita bisa sama-sama membagi nilai $m$ dan $g$ sehingga menjadi I.

$$
m g h_{1}=m g h_{2}+\frac{1}{2} m g r
$$

Karena $h 2$ adalah ketinggian benda ketika ada di puncak lintasan melingkar, maka nilai dari $h_{2}$ adalah sama dengan diameter atau 2 kali nilai jari-jari dari lintasan melingkar vertikal.

$$
\begin{aligned}
& h_{1}=2 r+\frac{1}{2} r \\
& h_{1}=2,5 r
\end{aligned}
$$

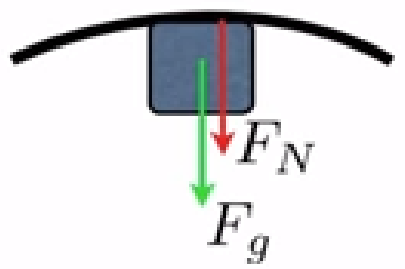

Gambar 6. Diagram benda ketika berada diatas lintasan melingkar vertikal.

Hasil analisis di atas untuk mengetahui ketinggian minimal yang dibutuhkan agar benda tidak terjatuh dari lintasan. Benda yang melintasi lintasan tentu harus melewati batasan minimal dari ketentuan yang ada jika tidak benda akan terjatuh dari lintasan. Ketinggian minimal benda jika dihitung secara manual untuk lintasan melinggar dengan diameter $30 \mathrm{~cm}$ maka dihasilkan.

$$
h_{1}=2,5=2,5 \times 0,15=0,375 \mathrm{~m}
$$

Untuk menentukan kecepatan minimal benda digunakan persamaan (I9) dan untuk mengetahui ketinggian minimal benda digunakan persamaan (24). Bila dihitung secara manual maka kecepatan minimal benda yang harus dicapai pada eksperimen adalah

$$
v=\sqrt{g r}=\sqrt{9,8 \times 0,15}, v=\sqrt{1,47}=1,21 \mathrm{~m} / \mathrm{s}
$$

Berdasarkan hasil perhitungan manual atau perhitungan secara teori hasil yang di peroleh kecepatan minimal agar benda dapat melewati lintasan tanpa terjatuh adalah I,2 I $\mathrm{m} / \mathrm{s}$ dan ketinggian minimal benda agar tidak terjatuh dari lintasan adalah 0,375 meter.

Analisis gerak benda dengan menggunakan software tracker dilakukan dengan meletakan titik-titik analisis di

\begin{tabular}{|c|c|c|c|c|c|}
\hline Titik & $t(s)$ & $x$ & y & $\mathrm{v}(\mathrm{m} / \mathrm{s})$ & $\mathrm{a}\left(\mathrm{m} / \mathrm{s}^{\wedge} 2\right)$ \\
\hline I & 0 & -0.003039 & $-0.00458 \mathrm{I}$ & & \\
\hline 2 & 0.168 & -0.05788 & $-0.0437 \mathrm{I}$ & & \\
\hline 3 & 0.202 & $-0.08 \mathrm{II}$ & -0.05919 & 0.926 & \\
\hline 4 & 0.236 & $-0 . \mathrm{I}$ I2 & -0.07467 & I. 202 & 6.309 \\
\hline 5 & 0.269 & $-0 . \mathrm{I} 5 \mathrm{I}$ & $-0 . \mathrm{I}$ & I. 364 & $5.8 \mathrm{I} 3$ \\
\hline 6 & 0.303 & -0.184 & $-0 . \mathrm{I} 3 \mathrm{I}$ & I. 496 & 9.904 \\
\hline 7 & 0.337 & -0.228 & -0.165 & $2.0 \mathrm{II}$ & 6.908 \\
\hline 8 & 0.37 & -0.288 & $-0.2 \mathrm{I} 9$ & 2.09 & 3.454 \\
\hline 9 & 0.404 & -0.334 & -0.258 & 2.065 & 9.65 \\
\hline IO & 0.438 & -0.393 & -0.309 & 2.793 & I 7.42 \\
\hline II & 0.472 & -0.473 & -0.384 & 3.304 & $\mathrm{I} 2.4 \mathrm{I}$ \\
\hline I2 & 0.505 & $-0.55 \mathrm{I}$ & -0.467 & 3.549 & 5.858 \\
\hline $\mathrm{I} 3$ & 0.539 & -0.646 & -0.549 & $3.57 \mathrm{I}$ & $\mathrm{I} 2.8 \mathrm{I}$ \\
\hline I4 & 0.573 & -0.739 & -0.616 & 3.449 & 22.15 \\
\hline I5 & 0.606 & -0.847 & -0.665 & $3.52 \mathrm{I}$ & 27.88 \\
\hline I6 & 0.64 & -0.969 & -0.676 & 4.062 & 29.68 \\
\hline I7 & 0.674 & -I.I2I & -0.673 & $3.9 \mathrm{II}$ & 36.77 \\
\hline I8 & 0.707 & $-\mathrm{I} .224$ & $-0.6 \mathrm{II}$ & 2.825 & 50.88 \\
\hline 19 & $0.74 \mathrm{I}$ & $-\mathrm{I} .265$ & -0.549 & 2.305 & 39.65 \\
\hline 20 & 0.775 & $-\mathrm{I} .265$ & -0.462 & 2.053 & 32.4 \\
\hline $2 \mathrm{I}$ & 0.808 & $-\mathrm{I} .232$ & $-0.4 \mathrm{I} 5$ & I. 874 & 27.37 \\
\hline 22 & 0.842 & -I.I7 & -0.379 & I. 942 & I6.65 \\
\hline 23 & 0.876 & -I.I I I & -0.366 & I.689 & I 4.85 \\
\hline 24 & 0.909 & -1.056 & $-0.37 \mathrm{I}$ & I.63I & I 3.32 \\
\hline 25 & 0.943 & $-\mathrm{I} .002$ & -0.384 & I. 836 & I6.69 \\
\hline 26 & 0.977 & -0.943 & -0.42 & $2.26 \mathrm{I}$ & I9.76 \\
\hline 27 & I.OI & -0.883 & -0.48 & $2.09 \mathrm{I}$ & 28.84 \\
\hline 28 & I.044 & -0.876 & -0.544 & 2.II5 & 32.82 \\
\hline 29 & I.078 & -0.896 & -0.622 & 2.266 & 28.05 \\
\hline 30 & I.I I I & -0.953 & -0.676 & 2.306 & 3I.03 \\
\hline $3 \mathrm{I}$ & I.I45 & $-\mathrm{I} .028$ & -0.704 & 2.652 & \\
\hline 32 & I.I79 & -I.I29 & -0.709 & & \\
\hline
\end{tabular}
sepanjang lintasan tempat benda bergerak. Titik-titik analisis yang diambil sebanyak 32 titik dari saat benda tidak bergerak di atas lintasan hingga benda selesai meluncur pada lintasan melingkar vertikal. Data yang didapat seperti berikut.



Adapun data lain berupa tabel yang berisi waktu, posisi benda, kecepatan benda dan percepatan benda sebagai berikut.

Tabel I. Data hasil tracking video 
Serta didapat data berupa grafik seperti berikut.

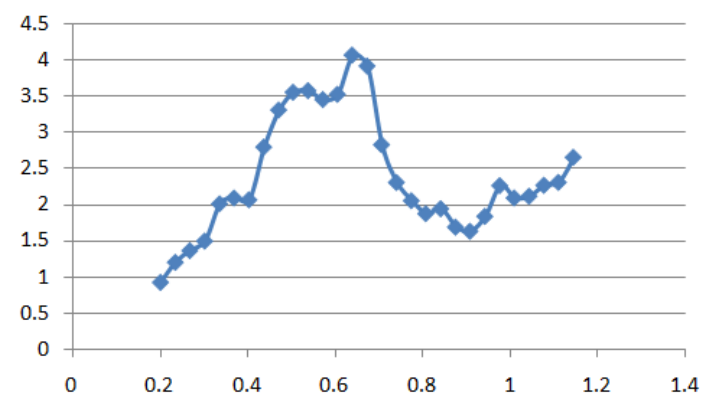

Gambar 7. Grafik hubungan antara kecepatan dan waktu.

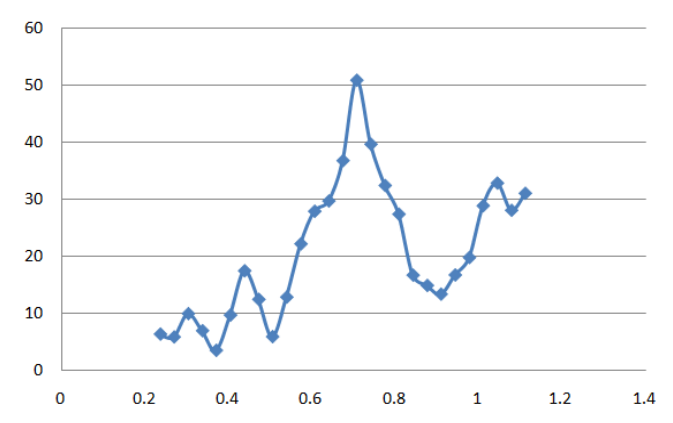

Gambar 8. Grafik hubungan antara percepatan dan waktu.

Hasil yang didapat melalui tracker yang ditampilkan hanya dari titik-titik tertentu saja seperti pada titik awal benda di titik ke I hingga titik ke 3 dan pada saat benda melintasi lintasan melingkar vertikal dan berada di posisi atas dan terbalik pada lintasan melingkar yaitu pada saat titik 25 hingga titik 28.

Berdasarkan data yang didapat dapat diketahui bahwa benda pada posisi awal memiliki nilai kecepatan dan percepatan nol seperti yang sudah diperkirakan sebelumnya. Benda juga memiliki kecepatan $2,26 \mathrm{~m} / \mathrm{s}$ pada titik 26 dimana pada saat itu benda pas berada di atas lintasan melingkar vertikal. Kecepatan yang didapat dari hasil perhitungan manual dan tracker menunjukkan bahwa kecepatan benda di atas kecepatan minimal yang seharusnya oleh karena itu benda tidak jatuh pada saat berada di atas lintasan melingkar vertikal.

Pembuktian secara manual atau menggunakan teori yang ada didapatkan hasil bahwa kecepatan yang diperoleh dari tracker mirip dengan perhitungan secara manual menggunakan persamaan (6) karena lintasan kita anggap sebagai bentuk lingkaran sempurna maka jarak lintasan dapat kita cari dengan menggunakan rumus keliling lingkaran dan (7) untuk mencari kecepatan ratarata benda sebagai berikut.

$$
S=2 \pi r=2 \pi \times 0,15=0,3 \pi \mathrm{m}
$$

Subtitusikan nilai jarak kedalam persamaan (7)

$$
v=\frac{0,3 \pi}{0,407}=2,31 \mathrm{~m} / \mathrm{s}
$$

Hasil perhitungan yang telah dilakukan secara manual dan menggunakan tracker menunjukkkan hasil yang relatif sama, hanya selisih 0,I5 ini membuktikan hasil yang didapat cukup akurat untuk dapat membuktikan bahwa persamaan-persamaan dan teori yang digunakan untuk eksperimen ini cukup valid.

Grafik yang didapat juga menunjukkan bahwa benda mengalami peningkatan kecepatan dan percepatan sebelum benda melewati lintasan melingkar vertikal. Pada saat melewati lintasan vertikal benda mengalami penurunan kecepatan dan percepatan. Ini sesuai grafik yang ada dimana garis grafik mengalami kenaikan lalu penurunan garis.

Hasil ini pun membuktikan bahwa agar Roller Coaster harus memiliki kecepatan yang cukup atau di atas kecepatan minimal agar aman dalam melewati lintasan melingkar vertikal. Setelah trek lintasan selesai dibuat, trek Roller Coaster dicoba digunakan dengan mengadakan praktik langsung dan memvideokan kegiatan.

\section{Kesimpulan}

Dari hasil penelitian yang telah dilakukan dapat diambil kesimpulan bahwa, agar benda dapat melintasi track tanpa terjatuh kecepatan minimal benda yang harus dicapai adalah I,2I m/s dan ketinggian minimal benda yang harus dipenuhi menurut hasil perhitungan manual adalah 2,5 kali dari jari jari lintasan melingkar (2,5R). Berdasarkan hasil percobaan menggunakan alat peraga, ketinggian benda agar tidak terjatuh dari lintasan adalah $50 \mathrm{~cm}$ dan analisis menggunakan software tracker di dapat bahwa kecepatan benda ketika bergerak pada lintsan adalah $2,26 \mathrm{~m} / \mathrm{s}$ juga hasil perhitungan manual kecepatan benda pada saat dilintasan adalah $2,3 \mathrm{I} \mathrm{m} / \mathrm{s}$.

Hasil kedua perhitungan tersebut dapat kita simpulkan bahwa persamaan-persamaan yang digunakan untuk mencari ketinggian dan kecepatan benda pada track melingkar vertikal sudah sesuai, karena kecepatan yang didapat dari hasil perhitungan mendukung hasil dari alat peraga yang memperlihatkan benda berhasil melewati lintasan tanpa terjatuh karena telah melewati batas minimum yang telah diperhitungkan.

\section{Ucapan Terimakasih}

Ucapan terima kasih kepada ibu Dandan Luhur Saraswati, M.Pd.Si sebagai dosen pembimbing dan tim desain pembuatan alat peraga ini yang telah banyak membantu hingga selesainya jurnal ini.

\section{Kepustakaan}

[I] Desy, Desnita, Raihanati. Prosiding Seminar Nasional Fisika (EJournal) SNF 2015. Pengembangan Alat Peraga Fisika Materi Gerak Melingkar Untuk SMA. Volume IV, Oktober 2015

[2] Giancoli, Physics: Principles with Applications Fifth Edition, Jakarta: Erlangga, 200I. 
[3] Young. Hugh D dan Roger Freedman, Fisika Universitas, Jakarta : Erlangga, 2004.

[4] Afriana. Jaka, Jurnal JRKPF UAD. Penggunaan Alat Sederhana SISI MISTIS dalam Pembelajaran Listrik Statis, Vol. 2 No. 2 Oktober 2015.

[5] Syafi'i. Muhammad dan Muhammad Nasir Jurnal Pendidikan Perancangan Dan Pembangunan Multimedia Interaktif Pembelajaran Fisika visualisasi Gerak Melingkar Beraturan Di Sekolah Menengah Atas (SMA) Vol 7, No 2, 2016

[6] M Tahsir, Jurnal JRKPF UAD Rancang Bangung Alat Praktikum untuk Menentukan Superposisi Gelombang Bunyi, Vol. 2 No. I April 2015. 